\title{
POSTOPERATIVE INTRA-ABDOMINAL HERNIA
}

\author{
CHARLES H. MAYO, M.D. \\ AND \\ JAMES A. H. MAGOUN, JR., M.D. \\ Fellow in Surgery, Mayo Foundation \\ ROCHESTER, MINN.
}

Moynihan, ${ }^{1}$ in his monograph on retroperitoneal hernia, directs attention to the possibility of herniation of the small intestine into the lesser peritoneal cavity through an abnormal aperture in the transverse mesocolon. Four such hernias have been reported, one by Boettcher ${ }^{2}$ in 1878. In 1885, von Hacker ${ }^{3}$ suggested the advisability of performing a gastrojejunostomy by the posterior route, making the anastomosis in the posterior wall of the stomach through an opening in the transverse mesocolon. Thus, seven years before the retrocolic method of gastrojejunostomy was advocated, attention had been directed to the possibility of the small bowel herniating through an opening in the transverse mesocolon. This fact, evidently, was lost sight of, because it was only after fatalities from such hernias that surgeons began to suture the stomach or jejunum to the transverse mesocolon. Mayo-Robson, ${ }^{4}$ Moynihan, ${ }^{1}$ Mikulicz, ${ }^{5}$ and others have reported cases of this type. In the older textbooks, ${ }^{6}$ suturing the opening in the transverse mesocolon to the stomach or jejunum before making the anastomosis (between the stomach and the jejunum) was advised. Of late years, this procedure has been reversed: the anastomosis is made first, and the sutures are placed afterward. MacArthur, ${ }^{7}$ however, for some time has reverted to the older method, considering it more advantageous to close the opening before performing the anas-

1. Moynihan, B. G. A.: Retroperitoneal Hernia, Ed. 2, London, Bailliere, Tindall and Cox, 1906, pp. 162-163.

2. Boettcher, A.: Hernia bursae omentalis mit im Mesocolon Transversum befindlicher Bruchpforte, Arch. f. path. Anat. u. Physiol. u. f. klin. Med. 72:642644, 1878.

3. Von Hacker: Zur Casuistik und Statistik der Magenresectionen und Gastro-enterostomieen, Arch. f. klin. Chir. 32:616-625, 1885.

4. Mayo-Robson, A. W., and Moynihan, B. G. A.: Diseases of the Stomach, London, Bailliere, Tindall and Cox, 1904, pp. 257-258.

5. Von Bergmann, E.: von Bruns, P., and von Mikulicz, J.: System of Practical Surgery, Philadelphia, Lea \& Febiger 5:439. 440, 444. 1904.

6. Von Bergmann, E.; von Bruns, P., and von Mikulicz, J.: Footnote 5. Kocher, T.: Operative Surgery, London, Adam and Charles Black, 1911, p. 571. Bryant, J. D.: Operative Surgery, New York, D. Appleton \& Co. 2:913, 1905.

7. MacArthur: Personal communication. 
tomosis, for in this manner the posterior portion of the aperture may be securely closed.

As the number of gastrojejunostomies increased, another form of internal hernia was observed. The small intestine slipped behind the loop of jejunum which is formed by every anastomosis, whether it is antecolic or retrocolic. Mikulicz ${ }^{5}$ recognized this and stated that the symptoms produced were due to compression of the root of the mesentery rather than to incarceration of the intestine. Mayo-Robson and Moynihan, ${ }^{4}$ in speaking of a case occurring after anterior gastrojejunostomy, reported by W. J. Mayo, ${ }^{8}$ say, "The passage of the small intestine through the loop formed by the juncture of the jejunum and stomach is probably only possible, certainly only probable, after the anterior operation."

Moschcowitz and Wilensky, ${ }^{9}$ in 1915 , collected seven cases from the literature reported by Steudel, ${ }^{10}$ Petersen, ${ }^{11}$ W. J. Mayo, ${ }^{8}$ Gray, ${ }^{12}$ Gordon, ${ }^{13}$ and Barker, ${ }^{14}$ and one of their own. Bryan, ${ }^{15}$ in 1920 , reported a similar case occurring twelve days after posterior gastrojejunostomy, in which the small intestine had passed from right to left, behind the anastomosis. The hernia was reduced by operation. Four days later, a similar herniation occurred and a third operation was necessary. The patient recovered. Deaver and Ashhurst ${ }^{16}$ reported a case, without details. They consider that the complication is more likely to occur after a long loop posterior gastrojejunostomy than after a short loop.

A summary of the ten cases reported from the literature shows that the hernia occurred in six cases following the posterior type of gastrojejunostomy (four with short loops and two with long loops); in two cases following the anterior type, and in two the type was not given.

8. Mayo, W. J.: Complications Following Gastro-Enterostomy, Ann. Surg. $36: 231-244,1902$.

9. Moschcowitz, A. V., and Wilensky, A. O.: Intestinal Obstruction Consecutive upon Posterior Retrocolic Gastro-Enterostomy, with Description of a Method to Avoid Similar Complications, Surg., Gynec. \& Obst. 21:390-393, 1915.

10. Steudel: Die in den letzten Jahren an der Czernyschen Klinik ausgeführten Magenoperationen und die Endresultate der früheren Operationen, Beitr. z. klin. Chir. 23:1-88, 1899.

11. Petersen, W.: Ueber Darmverschlingung nach der Gastro-Enterostomie, Arch. f. klin. Chir. 12:94-114, 1900.

12. Gray, H. M. W.: A Cause of Intestinal Obstruction After GastroEnterostomy, Lancet 2:526, 1904.

13. Gordon: Lancet 2:1477, 1905 .

14. Barker, A. E.: A Remarkable Sequel to a Case of Gastro-Enterostomy, Lancet 2:1277-1278, 1904.

15. Bryan, R. C.: Recurrent Internal Hernia Following Gastro-Enterostomy, Surg., Gynec. \& Obst. 30:82-85 (Jan.) 1920.

16. Deaver, J. B., and Ashhurst, A. P. C.: Surgery of the Upper Abdomen, Philadelphia, P. Blackiston's Son \& Co. 1:435, 1909. 
The more frequent occurrence of the hernia following the posterior operation might seem ambiguous were it not explained by the fact that a far greater number of posterior gastrojejunostomies are performed than anterior.

In seven cases, the hernia started on the right side and traveled toward the left. In one case it started on the left side and traveled toward the right. The time elapsing between the gastro-enterostomy and the second operation was six days in four cases; eight days in one; twelve days in two; fourteen days in one; one year in one, and two years in one. Four patients died, and four recovered; the final results were not stated with regard to two. We have not found, in the literature, mention of this form of internal hernia following colostomy. The possibility that this catastrophe may follow the Polya operation, anterior or posterior, should, however, be considered. Two cases of internal hernia following gastrojejunostomy, and one following colostomy are reported herewith.

\section{REPORT OF CASES}

CASE 1 (A 357800).-History. - Mr. R. D., aged 35, came to the clinic, May 11, 1921, complaining of having had a dull, heavy feeling in the epigastrium for ten years. The pain occurred from three to four hours after meals, and was relieved by food and soda. The patient was nauseated but did not vomit. The attacks lasted for about one month; he was then perfectly well for about six months. The bowels had been constipated for ten years.

Examination.-The patient had lost 11 pounds $(5 \mathrm{~kg}$.) in six months. The systolic blood pressure was 124 and diastolic 76 . The urine contained an occasional red blood cell. Blood examination revealed : hemoglobin 77 per cent.; erythrocytes, 4,690,000, and leukocytes, 9,300. The Wassermann reaction was negative. Examination of the gastric contents revealed: total acids, 42, and free hydrochloric acid, 40. Duodenal ulcer was revealed by the roentgen ray.

Operation.-May 18, 1921, an ulcer was found on the anterior wall of the duodenum just below the pylorus. It was impossible to perform a posterior gastro-enterostomy on account of the short mesentery of the transverse colon. The jejunum was brought up over the colon (12-inch [30.5 cm.] loop), and attached to the stomach, making an anterior gastro-enterostomy. The stomach and gallbladder appeared to be normal. The appendix, which was chronically inflamed, was removed.

Course.-The first three days of convalescence were uneventful. On the evening of the third day, however, the patient felt nauseated. The stomach tube was passed and 15 ounces (444 c.c.) of bile-stained fluid was recovered. During the night, he hiccuped and frequently vomited small amounts of bilestained fluid. The stomach tube was passed in the morning, and 24 ounces (710 c.c.) of the same kind of material was obtained. The evening of the fourth day, only one-half ounce (15 c.c.) of greenish material was recovered and the patient appeared to be better. On the following day, he was able to take ginger ale without nausea or vomiting. His condition remained about the same until the morning of the eighth day when 12 ounces ( 355 c.c.) of 
greenish fluid was recorered by the stomach tube. One ounce of castor oil was given, which was promptly vomited. The morning of the ninth day, the patient vomited 2 ounces ( 59 c.c.) of dark green fluid; and a few hours later 24 ounces $(710$ c.c.) was recovered by the stomach tube. The patient continued to be nauseated, and his general appearance indicated mechanical obstruction. The abdomen was opened and the condition described below was found.

The upper jejunum at a point distal to the gastro-enterostomy had slipped from right to left through the opening between the mesentery of the jejunum at the point where the gastro-enterostomy had been made and the transverse mesocolon. The entire small intestine from this point down to within a few inches of the ileocecal valve had followed the jejunum through the opening and was lying on the left side. This had produced torsion on the mesentery; and the jejunum for a distance of $1 \frac{112}{2}$ feet $(46 \mathrm{~cm}$.) distal to the gastroenterostomy was quite dark and distended. The intestine was pulled back through the opening and the obstructed bowel immediately regained its normal color. The opening through which the bowel had slipped was closed with interrupted catgut sutures. The gastro-enterostomy was adherent to the anterior abdominal wall and to the tissues surrounding it; and in elevating the stomach, the jejunum was separated from the stomach along the suture line of the gastro-enterostomy. This opening, which was about $2 \mathrm{~cm}$. long, was closed with two rows of chromic catgut. The loop of jejunum lying proximal to the gastro-enterostomy was not involved in the obstruction. When the wound was opened, seropurulent material appeared in the subcutaneous and deep tissues. The opening, which was made through the former incision, was closed with difficulty. The patient did not recover (Fig. 1).

CASE 2 (A 111382).-History.-Mr. J. C., aged 54, came to the clinic, July 25, 1914. He had complained of a dull aching pain in the epigastrium for two months. He had belched gas freely and his bowels had been constipated. The night before examination, he had taken a saline laxative. At 4 o'clock the following morning he was awakened with a very severe knifelike pain in the middle of the epigastrium, accompanied by vomiting. The abdomen was rigid; and two hypodermic injections of $1 / 4$ grain $(0.016 \mathrm{gm}$.) of morphin gave no relief. A diagnosis of perforating duodenal ulcer was made. At operation, an acute perforating ulcer of the duodenum was found. The perforation was closed with silk sutures and a posterior gastro-enterostomy (Mayo) was performed. The patient was well Aug. 23, 1920, when he had a sudden seizure of severe abdominal pain in the region of the umbilicus. He vomited a brownish, foul material continuously. $\mathrm{He}$ was given enemas and a purge by his family physician without relief.

Examination.-This revealed rigidity of the muscles of the upper left abdominal quadrant and tenderness to the left of the umbilicus. A provisional diagnosis of acute obstruction was made.

Operation.-Through a high rectus incision the upper jejunum, just distal to the gastro-enterostomy, was found to have slipped back between the portion of the jejunum which had been left between the origin of the jejunum and the point where the gastro-enterostomy was made and the transverse mesocolon. The entire jejunum and more than half of the ileum had followed this loop through the opening. The bowel was in good condition and was not discolored. There was a small amount of bloody fluid in the abdominal cavity. The bowel was pulled back and a few sutures were placed between the mesentery, at the 
origin of the jejunum and the transverse mesocolon, so as to close the opening. The patient's recovery was uneventful (Fig. 2).

CASE 3 (A 348789).-History:-Mr. A. M., aged 61, was examined Feb. 8, 1921. He had been operated on elsewhere in December, 1920, for hemorrhoids, and the diagnosis of cancer of the rectum was made. After the operation, there was less pain on defecation, but blood and mucus persisted,

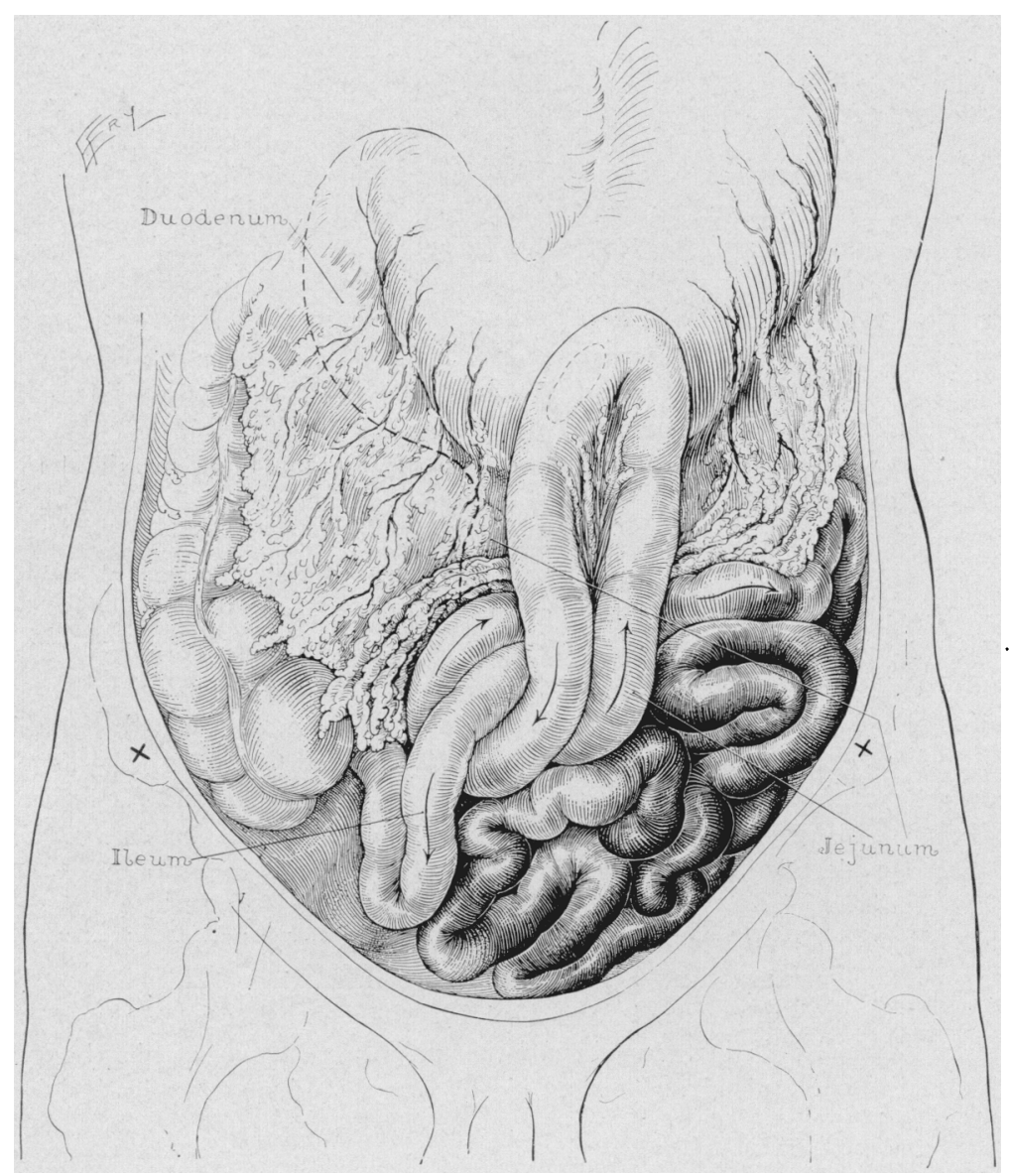

Fig. 1.-Hernia of the small intestine behind anastomotic locp of jejunum, following anterior gastrojejunostomy.

Examination.-The patient appeared to be fairly well nourished. The blood pressure was 154 systolic and 90 diastolic. The thyroid was enlarged. A large papillary mass appeared in the rectum. The urine showed a trace of albumin. Blood examination revealed: hemoglobin, 70 per cent.; erythrocytes, 4,500,000; leukocytes, 7,500. Roentgen-ray examination of the chest for metastasis was negative. 
Operation and Restit.-Feb. 17, 1921, a left rectus colostomy (Sistrunk method) was performed. The patient's convalescence was uninterrupted for six days, when his abdomen became markedly distended, especially on the left side. He passed very little gas and vomiterl greenish material several times. His pulse was 120 , his temperature was subnormal.

A second operation was performed, lebruary 26. The small intestine was greatly distended. The cecum and ascending colon were empty. Exploration

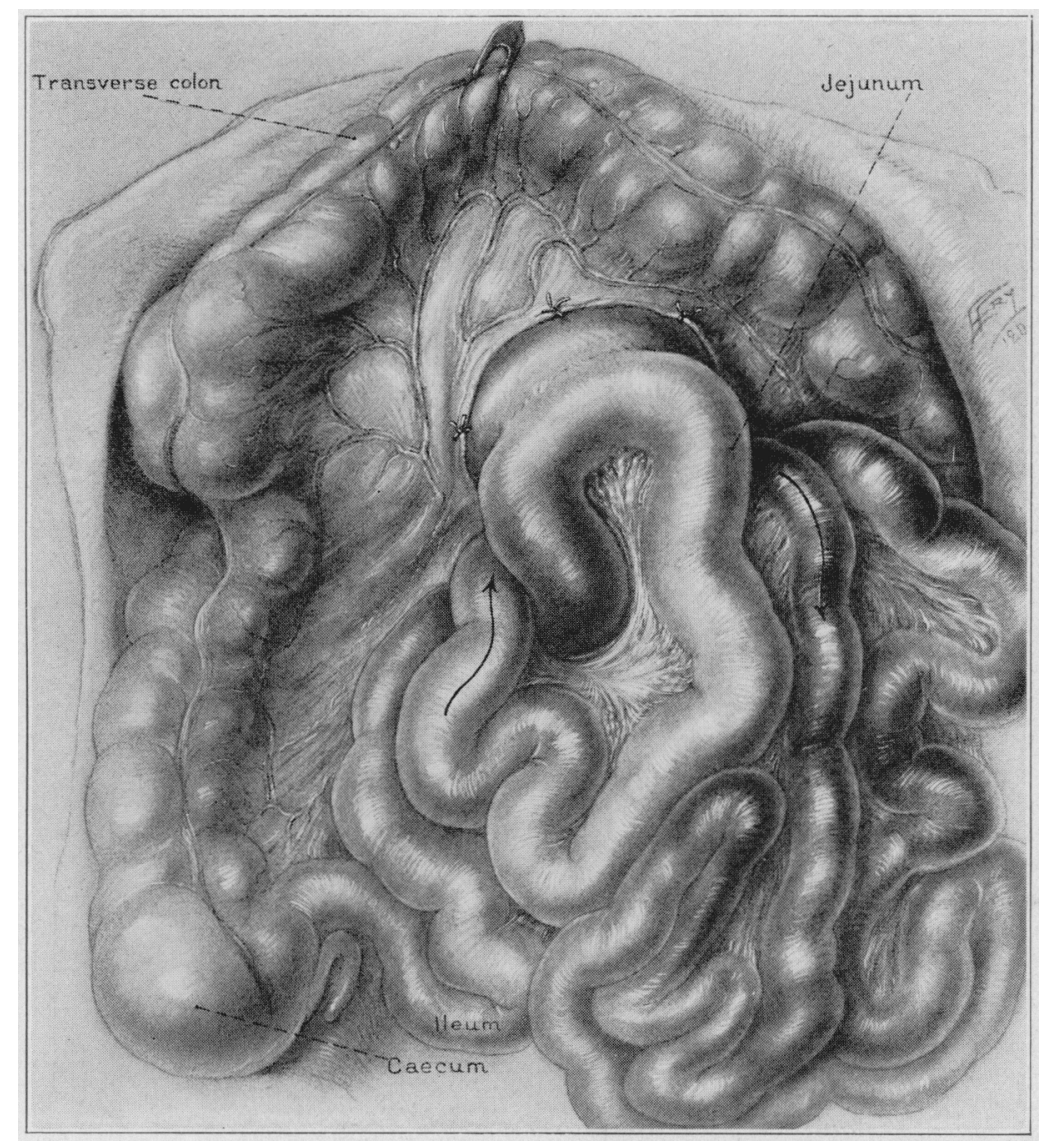

Fig. 2.-Hernia of the small intestine behind short anastomotic loop of jeimun following posterior gastrojejunostomy.

revealed that the entire small intestine had crawled completely around the colostomy (attachment of the sigmoid in the colostomy). The intestine, which was black, was reduced with difficulty and the abdominal wound was closed with through-and-through sutures. Color returned to the intestine after the reduction. Consicleral)le free fluid was found in the peritoneal cavity. Following the operation, the patient was given an intravenous injection of 400 c.c. of saline solution. He failed to rally and slied the same day (Fig. 3). 
COMMENT

The symptoms from this type of internal hernia do not appear to differ from the usual symptoms of high intestinal obstruction of acute onset. The complication is more likely to occur in cases in which some form of chronic obstruction has distended and enlarged the loops of bowel.

To prevent this form of intra-abdominal hernia, Moschcowitz and Wilensky advised suturing together the margins of the opening, using

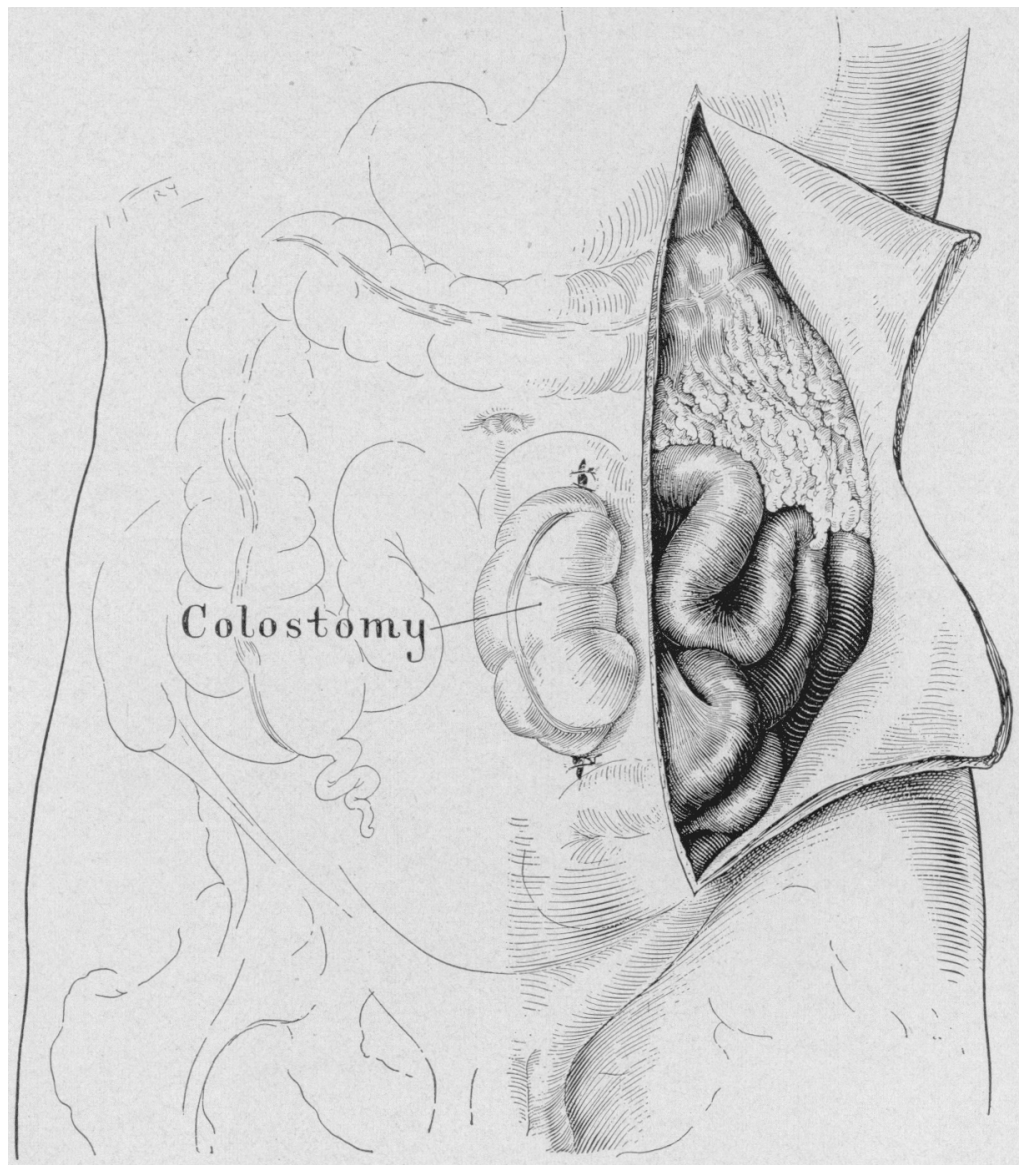

Fig. 3.-Hernia of the small intestine around colostomy.

the afferent loop of the jejunum and the inferior leaf of the mesentery. Bryan sutured the small intestine to the right lateral abdominal wall with several silk sutures. The latter method, however, should not be advocated. The practice followed in the clinic is described below:

In the anterior type of gastrojejunostomy, the abdominal toilet is carefully completed before the abdomen is closed. It is noted that no 


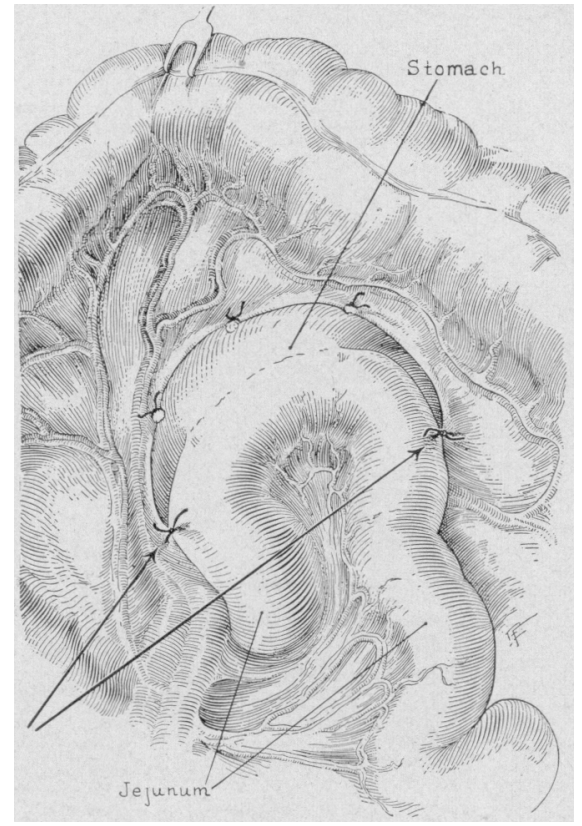

Fig. 4.-The arrows indicate the position of the sutures which would prevent the hernia shown in Figure 2.

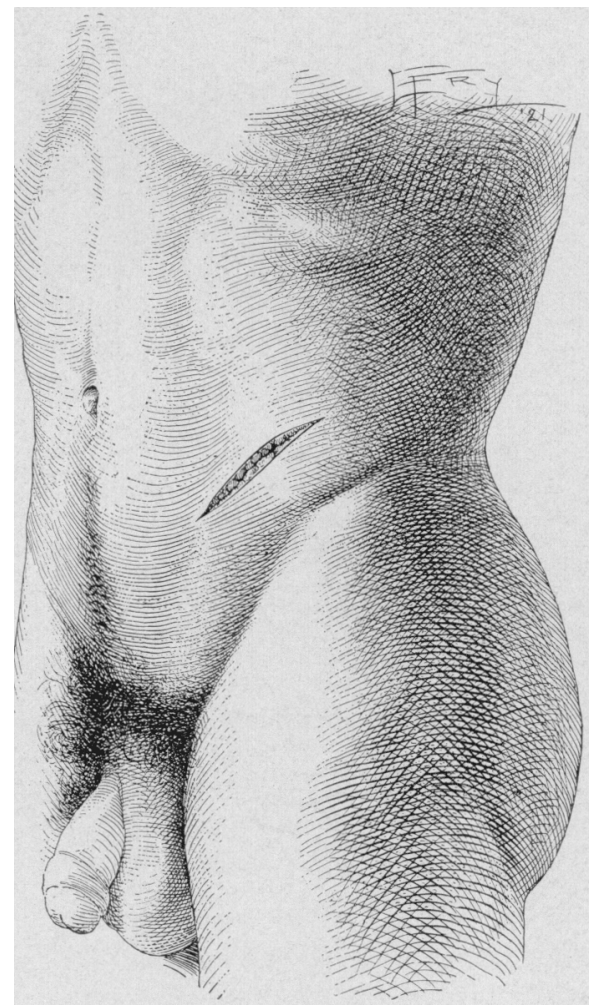

Fig. 5.-Incision for colostomy. 
loop of bowel hats passed behind the anastomosis either from right to left or from left to right. The omentum is placed around the loop of the anastomosis as securely as possible. Whether or not several sutures should be placed between the mesentery of the loop and the omentum is an open question.

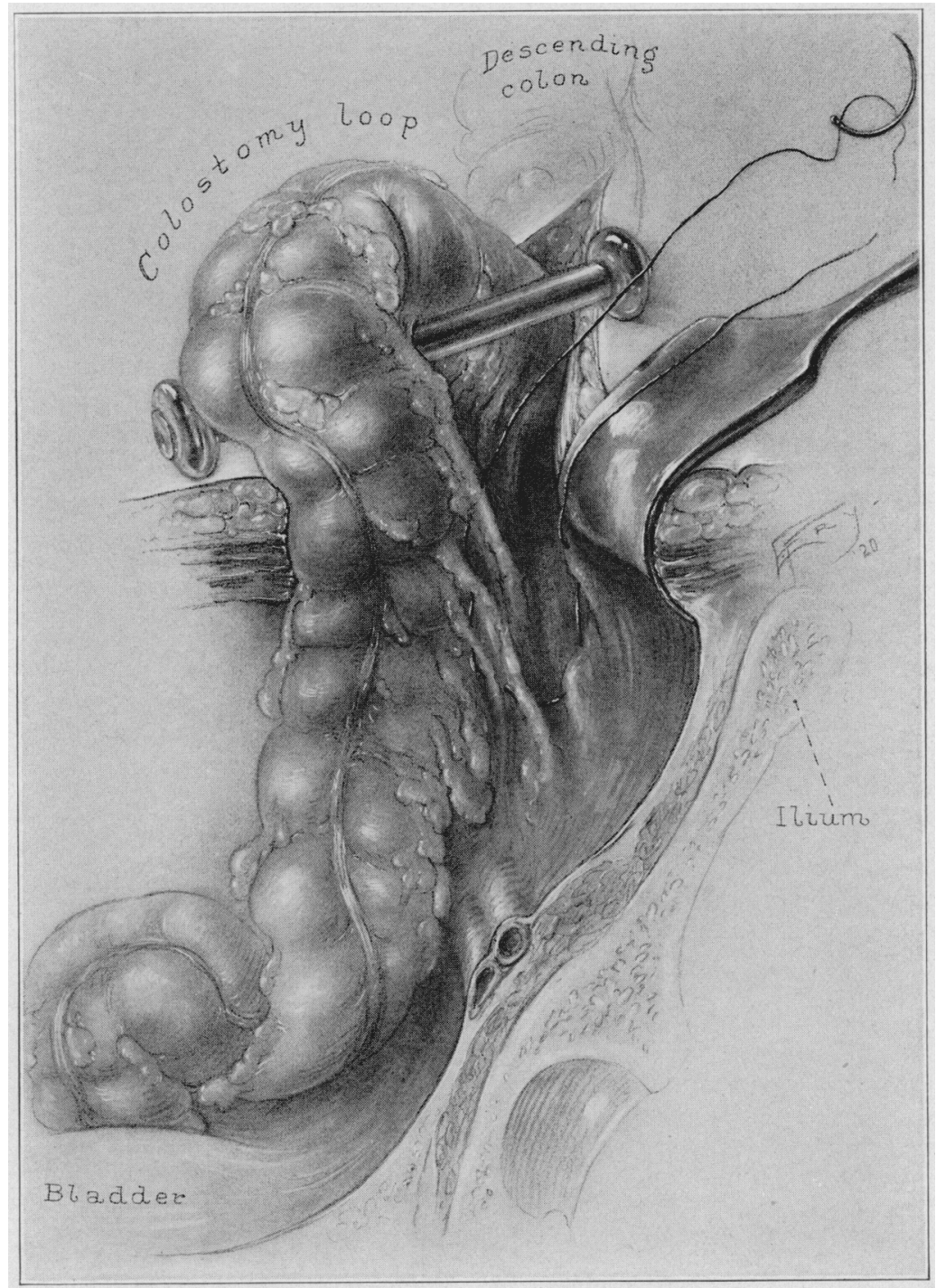

liig. 6.-Continuous suture between parietal peritoneum and mesosigmoid, closing space on suture of colostomy.

In the retrocolic short loop gastrojejunostomy (the long loop retrocolic method is no longer performed), the space behind the anastonotic 
loop through which herniation takes place is closed by placing a sutire between the afferent loop and the transverse mesocolon on the stomach about $2.5 \mathrm{~cm}$. above the gastrojejunal juncture, and another suture 2.5 cm. below (Fig. 4).

To prevent herniation following colostomy, the colostomy is made far to the left, on a line about one third of the distance between the left anterior superior spine and the umbilicus (Fig. 5). The MaydlLittlewood type of colostomy is usually employed. After the loop of

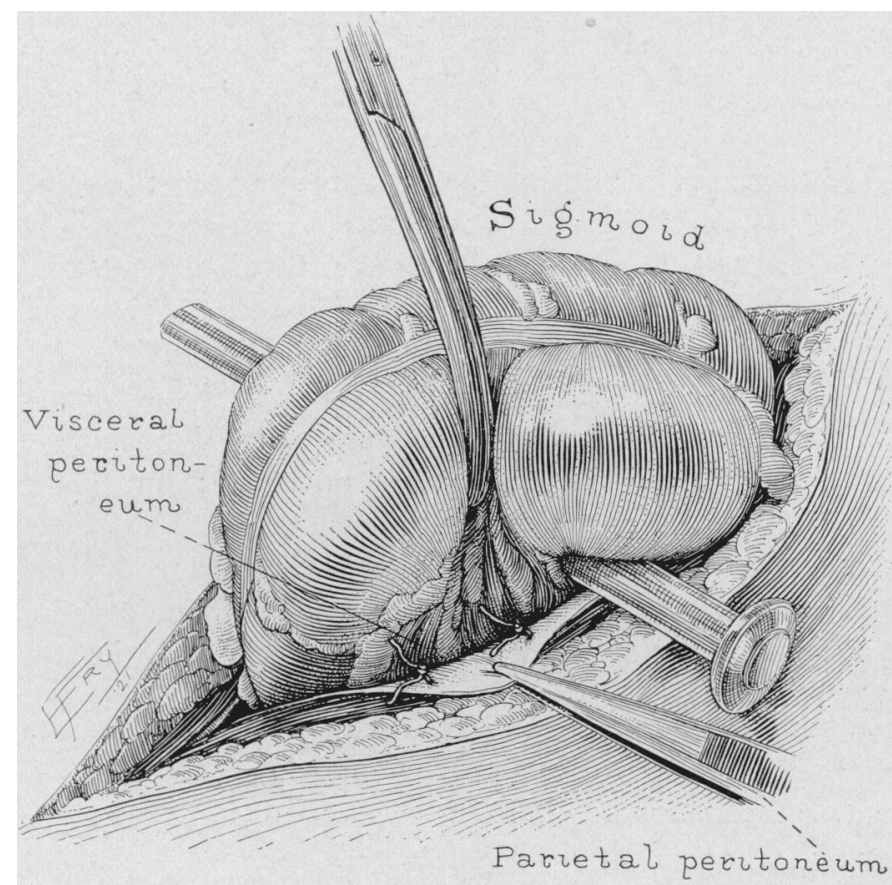

Fig. 7.-Two interrupted sutures through cut edge of parietal peritoneum and upper portion of mesosigmoid to prevent retraction of the colostomy loop.

sigmoid has been brought out of the abdomen, the mesosigmoid is sutured to the left parietal peritoneum by a continuous puckering suture (Fig. 6). Two interrupted sutures are then placed at the juncture of the sigmoid and its mesentery and just below the outer cut edge of peritoneum (Fig. 7). This procedure makes it impossible for the small intestine to pass around the colostomy, either from above or below. Such technic, especially if the small intestine is distended, tends to prevent postoperative complications, which, although rare, are extremely severe and result in a high mortality. 